\title{
ANÁLISE DAS PERDAS DE ÁGUA E SOLO EM UM VERTISSOLO CROMADO SOB DIFERENTES SISTEMAS DE MANEJO*
}

\author{
WATER AND SOIL LOSS IN A VERTISOL UNDER DIFFERENT \\ MANAGEMENT SYSTEMS
}
ANÁLISIS DE LAS PÉRDIDAS DE SUELO Y AGUA EN UN VERTISSOLO BAJO DIFERENTES SISTEMAS DE GESTIÓN

\author{
Richarde Marques da Silva - Universidade Federal da Paraíba - João Pessoa - Paraíba - Brasil \\ richarde@geociencias.ufpb.br \\ Celso Augusto Guimarães Santos - Universidade Federal da Paraíba - João Pessoa - Paraíba - Brasil \\ celso@ct.ufpb.br
}

\section{Resumo}

A erosão dos solos é uma das principais preocupações relacionadas ao manejo de solos tropicais, e o escoamento superficial, o responsável pelo transporte e deposição desses sedimentos. Diante desse fato, 0 presente trabalho busca descrever as perdas de água e solo em parcelas de erosão na Bacia Experimental de São João do Cariri - BESJC, localizada no semiárido do estado da Paraíba. Os dados sobre a perda de água e sedimento foram obtidos em duas parcelas de erosão de $100 \mathrm{~m}^{2}$, com sistemas de manejo diferenciados: uma com solo exposto (Parcela 1) e outra com vegetação do tipo caatinga (Parcela 2), em um período de três anos (1999-2002) e depois mantida com solo exposto (2003-2009). Os resultados de erosão mostraram que a erosão média na Parcela 1 foi de 0,22 ton/ha, enquanto na Parcela 2 foi em torno de 0,09 ton/ha, indicando a influência e a importância da cobertura vegetal do tipo caatinga e a adequação do manejo do solo em relação à erosão hídrica dos solos na região semiárida.

Palavras-chave: cobertura vegetal, perda de água e solo, erosão, semiárido.

\section{Abstract}

Water erosion is one of the main worries linked to tropical soil management, surface runoff being responsible for sediment transportation and bedding particles. This study aims to describe the water and sediment losses under various types of cover-management in São João do Cariri Experimental Basin - BESJC, located in the semiarid region of Paraíba State. The field data of runoff and sediment yield were collected in two plots of $100 \mathrm{~m}^{2}$ with different surface covers: one with bare soil (1999-2009) and another with common grass cover during three years (1999-2002) but later it was maintained with cleared bare soil (2003-2009). The erosion results showed that erosion in the Plot 1 was 0.22 ton/ha, while in the Plot 2 was 0.09 ton/ha, which shows the influence of the vegetation cover and management system on the erosion process in semiarid lands.

Keywords: vegetal cover, soil and water loss, erosion, semiarid region.

\section{Resumen}

La erosión hídrica es una de las principales preocupaciones relacionadas con la gestión de los suelos tropicales y la escorrentía responsable del transporte y deposición de sedimentos. Frente a hizo, este trabajo tiene como objetivo describir la pérdida di agua e sedimentos en parcelas experimentales en la Cuenca Experimental de São João do Cariri - BESJC, ubicada en la región semiárida del estado de Paraíba. Los datos de pérdida de agua y sedimento fueron obtenidos en dos parcelas de erosión de $100 \mathrm{~m}^{2}$ con el sistema de gestión y mantillo

\footnotetext{
* Pesquisa financiada pelo CNPO, por meio de Bolsa de Produtividade em Pesquisa.
} 
diferenciada: una mantiene con suelo desnudo (1999-2009) y una con vegetación nativa (caatinga), en un período de tres años (1999-2002) y luego mantuvo con suelo desnudo (2003-2009). Los resultados de erosión muestran que la erosión media en la Parcela 1 fue 0,22 ton/ha, mientras que en la Parcela 2 fue de 0,09 ton/ha, lo que demuestra la influencia de la vegetación y sistema de relación sobre la erosión en las zonas semiáridas. Palabras clave: vegetación, pérdida de agua e suelo, erosión, región semiárida.

Introdução

A erosão hídrica do solo é um processo natural influenciado pela chuva, pelo solo, pela topografia, pela cobertura e manejo do solo e pelas práticas conservacionistas. Entre esses fatores, a cobertura e o manejo do solo apresentam maior influência sobre a erosão hídrica do que os demais (Guadagnin et al., 2005). A erosão pode ser definida como o desprendimento e a deposição das partículas de solo pelos processos que são influenciados pelo clima, pelo solo, pela topografia e pela cobertura vegetal (Freitas et al., 2008). A erosão dos solos é extremamente variável, temporal e espacialmente, e essa variabilidade deve-se às diferenças nas condições da superfície, ou seja, das características do solo e das condicionantes climáticas da região, que afetam diretamente o escoamento superficial.

Sobre a influência da cobertura vegetal nos processos de erosão, Silva et al. (2005) ressaltam que a vegetação pode atuar de duas maneiras: a) reduzindo o volume de água que chega ao solo, por meio da interceptação; b) alterando a distribuição do tamanho das gotas de chuva, afetando, portanto, a energia cinética da chuva.

Entre os principais problemas enfrentados para a realização de estudos de perda de água e sedimento, estão: a) a obtenção de dados que permitam descrever a variabilidade espacial das variáveis de chuva, vazão e erosão, em razão das dificuldades de monitoramento e dos custos de que a coleta desses dados necessita; b) a coleta e o tratamento dos dados obtidos em campo; c) a calibração de modelos matemáticos para a predição de erosão e escoamento superficial para bacias da região semiárida. Como alternativas para suprir os problemas da obtenção de dados, foram implantadas bacias experimentais em diversos locais da região Nordeste para aquisição de dados hidrológicos, a exemplo da Bacia Experimental de São João do Cariri (BESJC).

Nas regiões semiáridas, como é o caso de grande parte do estado da Paraíba, a erosão dos solos é um sério problema, e, por isso, os aspectos 
físicos do solo e suas relações ambientais e socioeconômicas vêm sendo estudados nas últimas décadas por órgãos e pesquisadores, como apresentado em Albuquerque et al. (2005) e Souza et al. (2009, 2010). A região semiárida compreende uma vasta porção da região Nordeste do Brasil (946 mil km²) e caracteriza-se, do ponto de vista geoambiental, pela diversidade de suas paisagens, tendo como elemento marcante, no seu quadro natural, a condição de semiaridez que atinge grande parte do seu território e a alta variabilidade pluviométrica espacial e temporal inerente a esse tipo climático.

A vegetação de caatinga ocupa toda a região semiárida nordestina, sendo 297 mil km² com caatinga hiperxerófila, 247 mil km² com

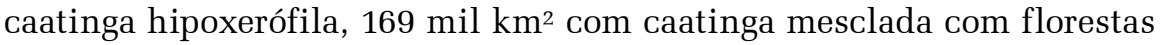

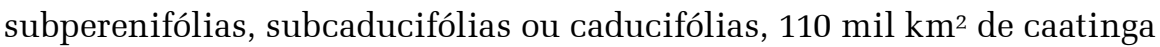
mesclada com cerrado, $101 \mathrm{mil} \mathrm{km}^{2}$ com mistura de caatinga, floresta e cerrado e $22 \mathrm{mil} \mathrm{km²}$ com caatinga e campos de altitude (MMA, 2003). Segundo Freitas et al. (2008), a capacidade da vegetação do tipo caatinga de suportar os impactos provocados pela chuva e seu consequente escoamento superficial, na forma de erosão hídrica, é muito pouco conhecida e carece de mais estudos.

Assim, este estudo busca contribuir para os conhecimentos sobre as perdas de solo e água em um solo do tipo Vertissolo Cromado e sobre a influência da cobertura vegetal do tipo caatinga na erosão dos solos na região semiárida.

\section{A área de estudo e experimentos}

A Bacia Experimental de São João do Cariri (BESJC) possui uma área de aproximadamente $15 \mathrm{~km}^{2}$, inserida entre as coordenadas $7^{\circ} 22^{\prime} \mathrm{de}$ latitude Sul e $36^{\circ} 31^{\prime}$ de longitude Oeste (Figura 1). A BESJC foi instalada em 1997 e conta atualmente com o apoio de diversos órgãos financiadores, como Finep, CT-HIDRO e CNPq, com os projetos Implantação de Bacias Experimentais no Semi-árido (IBESA) e Bacias Experimental e Representativa da Rede de Hidrologia do Semiárido (BEER).

Segundo a classificação climática de Köeppen, o clima da região enquadra-se no tipo BSh, denominado semiárido, caracterizado pela insuficiência e irregularidade das precipitações pluviais e pela ocorrência de temperaturas elevadas. A Figura 2 mostra a variabilidade da precipita- 


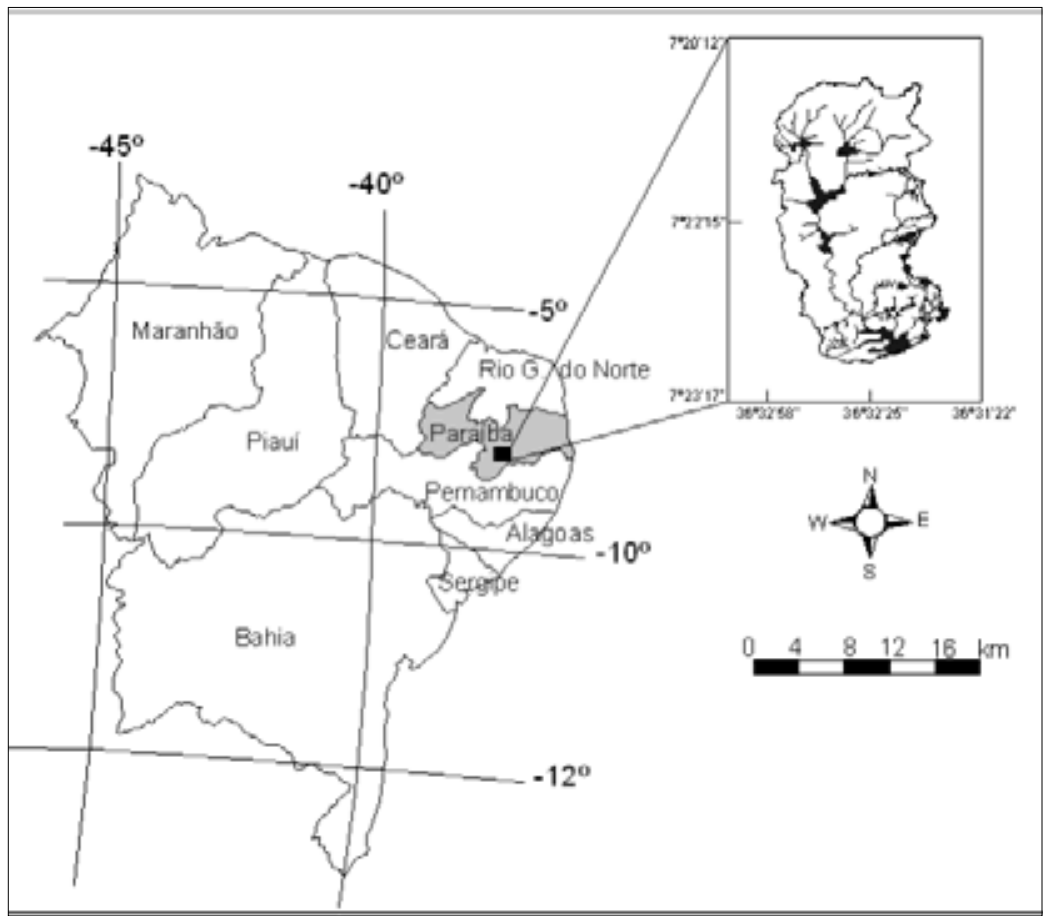

FIGURA 1- Localização da Bacia Experimental de São João do Cariri no Estado da Paraíba Fonte: Santos et al. (2011).

ção anual média na bacia, observada no período de 1986 a 2010, com precipitação anual em torno de $460 \mathrm{~mm}$. Para isso, foi utilizada toda a série de dados existentes no experimento, uma vez que os dados de outro local (outra escala espacial) não poderiam ser utilizados para o propósito do estudo, pois o foco do artigo é a modelagem sedimentológica (vazão-erosão), ou seja, a relação dos eventos durante o período de obtenção de dados.

Na Figura 3 são apresentados os valores de precipitação mensal. Percebem-se nos meses de janeiro, fevereiro e julho de 2004 os mais altos valores, estando acima da média histórica. Os menores valores foram verificados nos meses de julho a dezembro.

A temperatura ao longo do ano varia entre $23{ }^{\circ} \mathrm{C}$ no mês de junho e $29{ }^{\circ} \mathrm{C}$ (máxima) nos meses de setembro a janeiro. A umidade relativa média anual é de aproximadamente 57\% (Santos et al., 2007). 


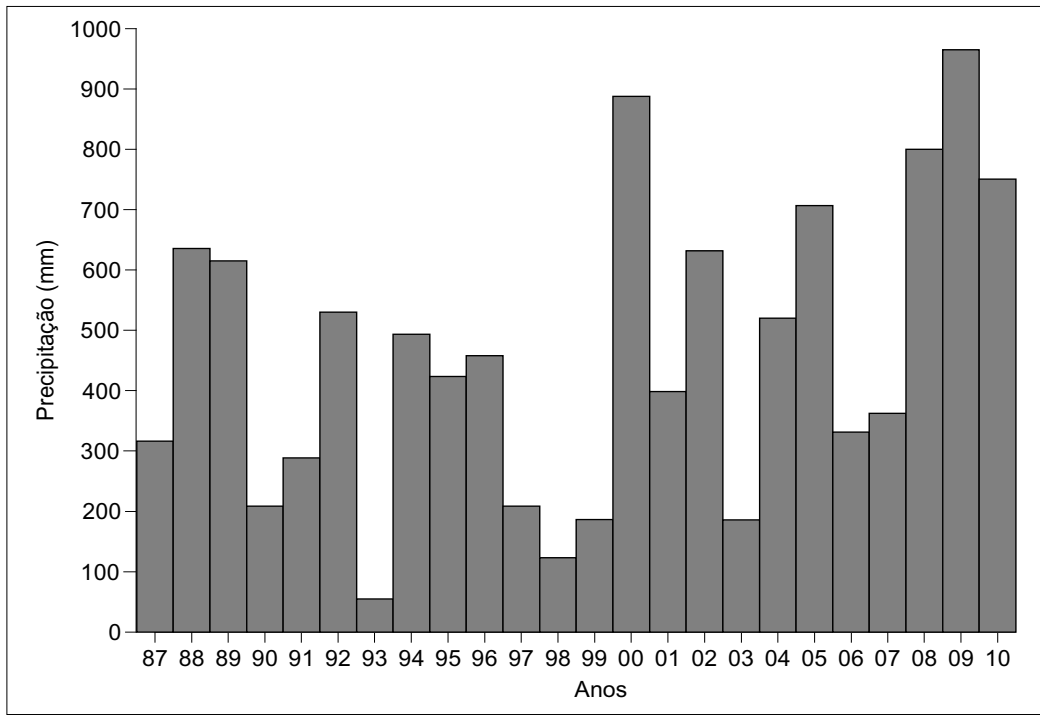

FIGURA 2 - Precipitação anual média na Bacia Experimental de São João do Cariri Fonte: Santos et al. (2011).

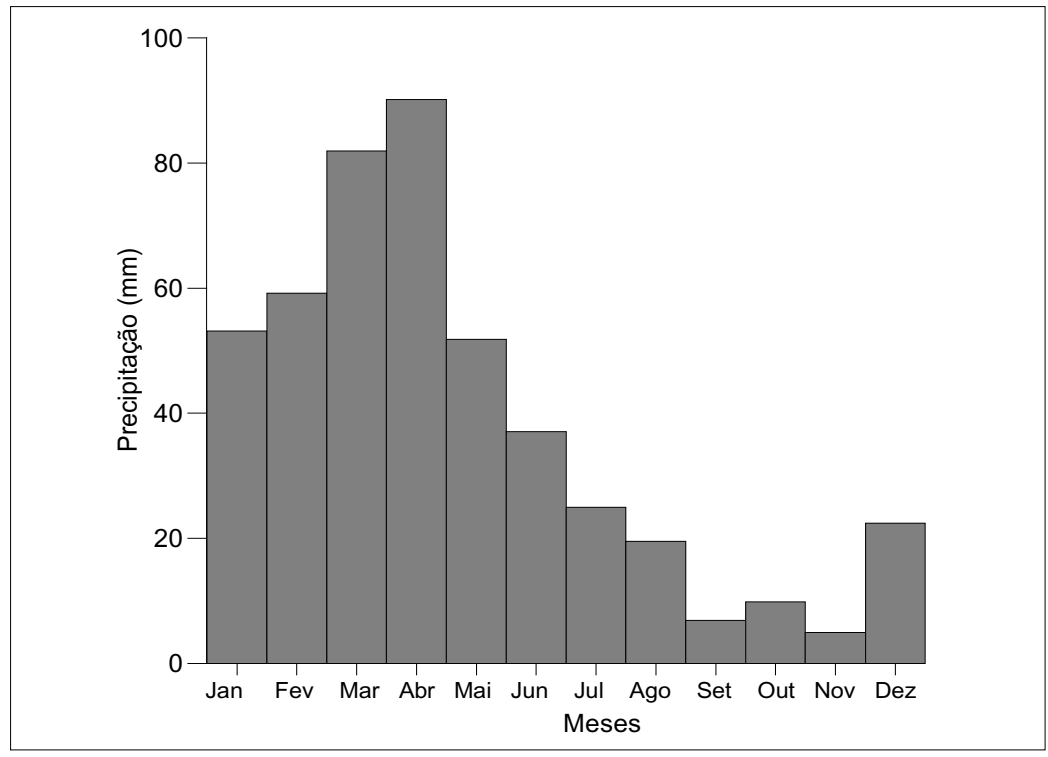

FIGURA 3 - Precipitação mensal média na Bacia Experimental de São João do Cariri Fonte: Santos et al. (2011). 
A BESJC é constituída por solos rasos, pouco porosos e predominantemente plásticos, subsolo derivado do embasamento cristalino, vegetação do tipo caatinga e relevo bastante ondulado, com altitudes variando entre 450 e $700 \mathrm{~m}$. Os principais tipos de solo encontrados na bacia são: Vertissolo Cromado, Luvissolo e Neossolo Litólico, com horizonte A fraco e textura argilosa e com vegetação do tipo caatinga hiperxerófila.

A avaliação da influência dos diferentes sistemas de manejo e cobertura do solo nas perdas de água e sedimento, na BESJC, foi realizada a partir da comparação dos dados observados de lâmina escoada e de erosão produzidos em duas parcelas de erosão com 100 m² $^{2}(4,5 \square 22,2 \mathrm{~m})$. Uma descrição detalhada das características das parcelas é apresentada na Tabela 1. As Figuras 4A e 4B mostram respectivamente a Parcela 1 (desmatada) e os detalhes dos tanques coletores, utilizados para armazenar a produção de sedimentos e as perdas de água.

TABELA 1 - Características das parcelas da Bacia Experimental de São João do Cariri

\begin{tabular}{|c|c|l|c|}
\hline Parcela & $\begin{array}{c}\text { Declividade } \\
\text { Média (\%) }\end{array}$ & $\begin{array}{l}\text { Sistema de Manejo/ } \\
\text { Cobertura do Solo }\end{array}$ & Período de Dados \\
\hline 1 & 3,4 & Solo exposto & $1999-2009$ \\
\hline \multirow{2}{*}{2} & \multirow{2}{*}{3,6} & $\begin{array}{l}\text { Vegetação rasteira com } \\
\text { cobertura morta }\end{array}$ & $1999-2002$ \\
\cline { 2 - 4 } & & Solo exposto & $2003-2009$ \\
\hline
\end{tabular}

Fonte: Srinivasan et al. (2004)
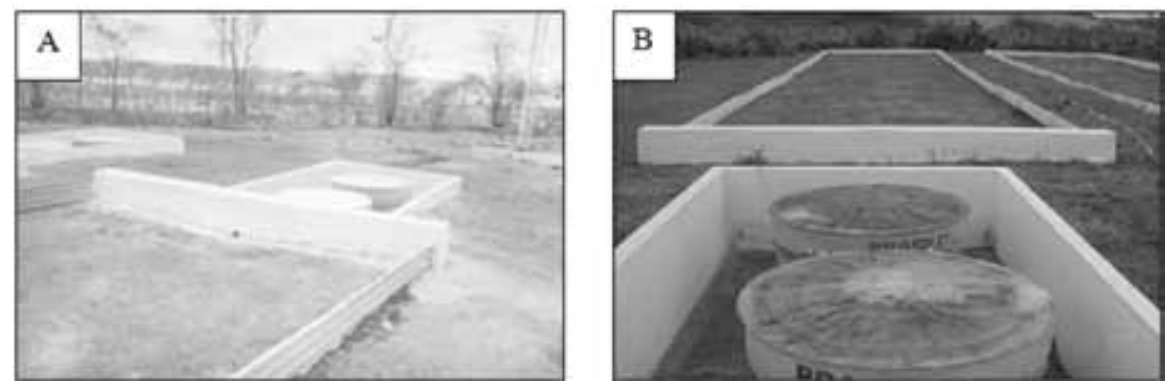

FIGURA 4 - Parcelas de erosão na Bacia Experimental de São João do Cariri: (A) Vista da Parcela 1 (solo exposto) e (B) Detalhes dos tanques para coleta de dados Fonte: Srinivasan et al. (2004). 
Na BESJC existem três microbacias e quatro sub-bacias instrumentadas, onde são coletados dados de erosão e lâmina escoada. Neste estudo foram utilizados dados da microbacia 1 - MB1, que possui área de 0,18 ha. A MB1 foi escolhida por possuir grande número de eventos de lâmina escoada e erosão observados.

Foram utilizados dados de 237 eventos de precipitação, lâmina escoada e erosão, coletados entre 14/3/1999 e 26/08/2009. Os dados de precipitação foram obtidos em um pluviógrafo localizado na bacia e os dados de lâmina escoada e erosão, coletados no exutório da MB1. Cabe destacar que os dados observados de chuva, lâmina escoada e erosão fazem parte do acervo de dados coletados na BESJC, para as escalas de parcela e de microbacia.

\section{Resultados e discussão}

Os resultados apresentados neste estudo foram obtidos em diferentes sistemas de manejo e cobertura superficial, em um solo do tipo Vertissolo Cromado no semiárido do estado da Paraíba. A Tabela 2 apresenta os valores anuais e médios e os testes estatísticos de precipitação e das perdas de água e solo, para as parcelas na BESJC. A partir dos dados observados de lâmina escoada, nota-se que a Parcela 1 obteve desvio padrão da lâmina escoada igual a $9,7 \mathrm{~mm}$, enquanto na Parcela 2 foi observado desvio padrão da ordem de $8,9 \mathrm{~mm}$, uma redução da perda de água igual a $23,8 \% \mathrm{~mm}$.

As perdas de água anuais totais apresentaram uma variação de 2,1 a 12,0 mm, para as condições de solo descoberto (Parcela 1) e 0,7 a 10,8 $\mathrm{mm}$, para a parcela com cobertura vegetal nativa (Parcela 2). As menores perdas de água foram observadas para o sistema com cobertura vegetal nativa (caatinga), o que pode ser explicado pela interceptação das gotas de chuvas pelo dossel da vegetação, que mesmo não possuindo um extrato vertical muito diversificado protege o solo.

A maior quantidade de perda de água na caatinga justifica-se pela maior resistência físico-hidráulica ao escoamento criada pela sua copa e pela camada de serrapilheira, traduzida no maior valor do coeficiente de rugosidade hidráulica. Resultados semelhantes para perdas de água em diferentes sistemas de manejo e cobertura do solo também foram constatados por Martins et al. (2003), Guadagnin et al. (2005) e Freitas et al. (2008). 
TABELA 2 - Valores anuais e médios de precipitação e de perdas de água e solo nas parcelas de erosão

\begin{tabular}{|c|c|c|c|c|c|c|c|}
\hline \multirow{2}{*}{ Ano } & \multirow{2}{*}{$\begin{array}{c}\text { Chuva } \\
\text { (mm) }\end{array}$} & \multicolumn{2}{|c|}{ Perdas de Água (mm) } & \multicolumn{3}{c|}{ Perdas de Solo (ton/ha) } \\
\cline { 3 - 8 } & Parcela 1 & Parcela 2 & $\begin{array}{c}\text { Redução } \\
\text { (\%) }\end{array}$ & Parcela 1 & Parcela 2 & $\begin{array}{c}\text { Redução } \\
\text { (\%) }\end{array}$ \\
\hline 1999 & 14,3 & 2,1 & 1,6 & 26,5 & 0,12 & 0,03 & 75,0 \\
\hline 2000 & 20,6 & 7,4 & 3,6 & 51,3 & 0,39 & 0,04 & 89,7 \\
\hline 2001 & 16,3 & 6,5 & 0,7 & 89,7 & 0,20 & 0,01 & 95,0 \\
\hline 2002 & 21,1 & 9,0 & 7,0 & 22,1 & 0,36 & 0,12 & 66,7 \\
\hline 2003 & 18,6 & 4,5 & 4,1 & 9,8 & 0,20 & 0,08 & 60,0 \\
\hline 2004 & 22,5 & 7,9 & 7,1 & 9,3 & 0,22 & 0,12 & 45,4 \\
\hline 2005 & 25,2 & 12,0 & 10,8 & 10,5 & 0,20 & 0,14 & 30,0 \\
\hline 2006 & 16,6 & 7,5 & 7,0 & 6,8 & 0,10 & 0,10 & 00,0 \\
\hline 2007 & 21,4 & 7,2 & 7,0 & 2,8 & 0,09 & 0,08 & 11,1 \\
\hline 2008 & 21,3 & 9,4 & 8,2 & 12,8 & 0,14 & 0,12 & 14,3 \\
\hline 2009 & 22,3 & 7,1 & 6,2 & 12,7 & 0,18 & 0,13 & 27,8 \\
\hline Média $^{20}$ & 20,5 & 7,7 & 5,9 & 23,8 & 0,22 & 0,1 & 59,1 \\
\hline DP $^{*}$ & 20,6 & 9,7 & 8,9 & - & 0,32 & 0,1 & - \\
\hline DM $^{* *}$ & 14,5 & 6,3 & 5,5 & - & 0,23 & 0,1 & - \\
\hline CV $^{* * *}$ & 1,0 & 1,3 & 1,5 & - & 1,42 & 1,7 & - \\
\hline & & $*$ Desvio padrão, ${ }^{* *}$ Desvio médio, ${ }^{* * *}$ Coeficiente de variação. & & \\
\hline
\end{tabular}

Esses resultados ressaltam o importante papel que a cobertura vegetal desempenha no controle das perdas de água por escoamento superficial, principalmente quando considerada a irregularidade temporal e espacial das chuvas na região semiárida no Nordeste do Brasil. Comparando-se apenas o período em que as duas parcelas detinham sistemas de manejo e cobertura do solo distintos (1999-2002), percebe-se uma diferença considerável entre os valores observados, com redução variando de 22,13 a 89,74\% (Tabela 2). A partir de 2002, com a retirada da caatinga, percebe-se um aumento gradual do escoamento.

No que tange à comparação dos dados de erosão nas duas parcelas, observou-se que o valor médio anual de erosão na Parcela 1, em relação ao valor médio da Parcela 2, foi aproximadamente oito vezes maior, apresentando valores médios de erosão de 0,2 e 0,09 ton/ha, respectivamente, com uma redução de perdas de solo de 59,1\% (Tabela 2). 
Considerando todo o período de dados existentes, as perdas de água registradas na Parcela 1 foram da ordem de 38,1\%, enquanto na Parcela 2 foram de 27,5\%, com a precipitação média anual de 20,5 mm (Tabela 2). Esses dados mostram que essas áreas, com o mesmo tipo de solo, apresentaram valores considerados próximos, uma vez que a cobertura vegetal, em boa parte do tempo, foi igual em ambas as parcelas, e com o crescimento dela houve maior interceptação da chuva, diminuição do escoamento e também do efeito splash, que origina o desprendimento das partículas de solo com o impacto das gotas de chuva.

As perdas de água de todos os eventos nas duas parcelas mostram que os eventos extremos de lâmina escoada foram semelhantes em ambas as parcelas, com exceção dos picos em alguns eventos isolados, variando entre 50 e $65 \mathrm{~mm}$. Nota-se também uma pequena diferença em relação aos valores das médias observadas, 7,7 $\mathrm{mm}$ na Parcela 1 e 5,9 $\mathrm{mm}$ na Parcela 2 (Figura 5).

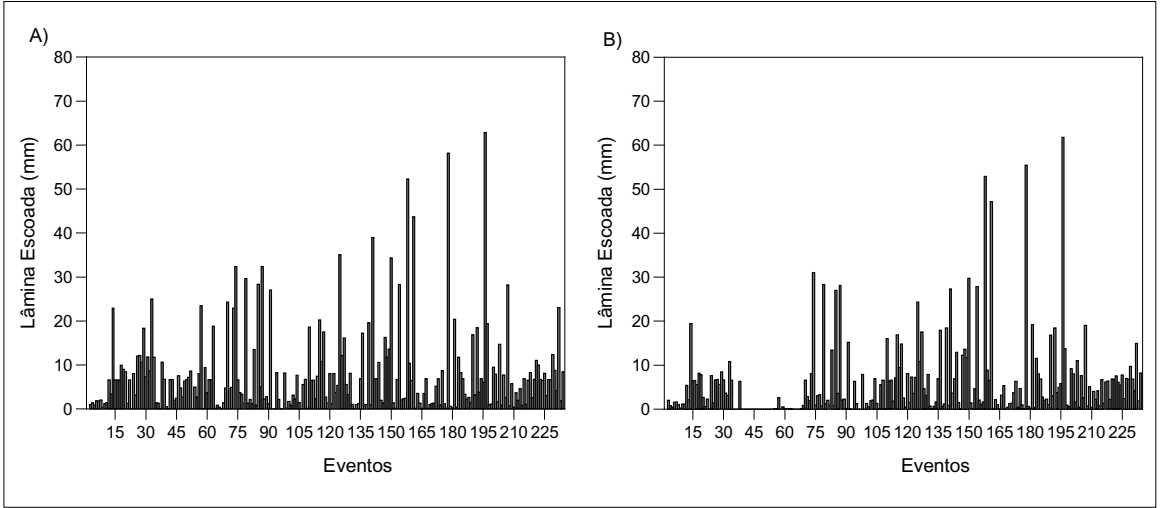

FIGURA 5 - Lâmina escoada nas parcelas de São João do Cariri: (A) Parcela 1 e (B) Parcela 2 Fonte: Santos et al. (2007).

Os valores apresentados referentes às perdas de solo (Tabela 2) podem ser explicados em parte pelo fato de os solos da região serem pouco profundos e hipereutróficos e possuírem argila de atividade alta, relevo ondulado e rochosidade. Essas características são fatores limitantes para o uso agrícola e influenciam diretamente na rápida formação de sulcos e no pequeno espaço de tempo para o começo do escoamento. 
Na Parcela 1, os valores observados de erosão variaram entre 0,0 e 1,9 ton/ha, enquanto na Parcela 2, os valores observados alteraram entre 0,0 e 0,1 ton/ha. A representação gráfica de todos os eventos registrados nas duas parcelas da BESJC mostra que os eventos mais extremos de perdas de solo foram distintos, quando comparados evento a evento em cada parcela (Figura 6).
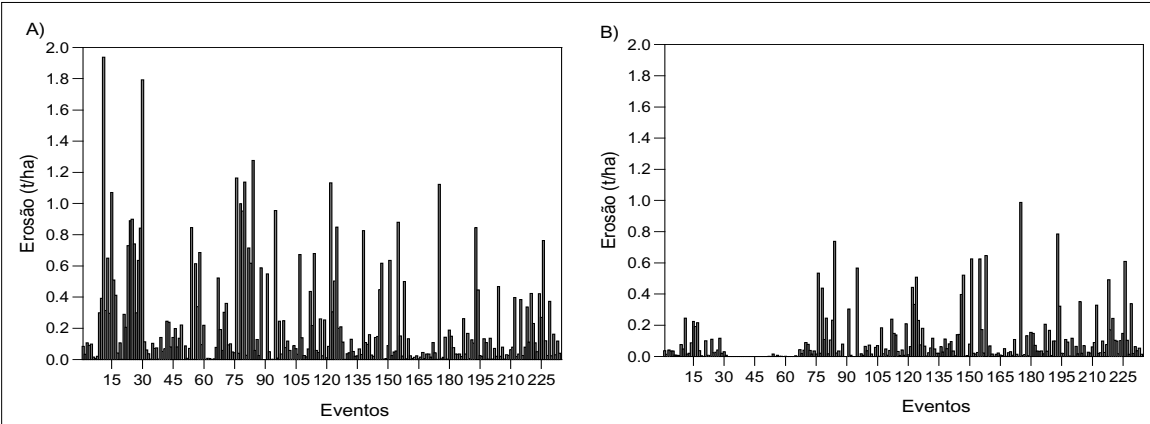

FIGURA 6 - Valores de perdas de solo nas parcelas de erosão em São João do Cariri:

(A) Parcela 1 e (B) Parcela 2

Fonte: Santos et al. (2007).

Na Figura 7 são apresentadas as relações entre os dados observados de precipitação e erosão medidos nos eventos que geraram perdas de solo, ocorridos nas Parcelas 1 e 2. Na Parcela 1, os maiores valores registrados foram da ordem de 1,9 ton/ha, enquanto na Parcela 2, os maiores valores não atingiram 1,0 ton/ha. A caatinga e sua rugosidade hidráulica imposta ao escoamento superficial determinaram a redução exponencial das perdas de solo, mostrando, assim, a eficácia da cobertura vegetal nativa da região contra as perdas de solo.

Na parcela com solo exposto, a superfície do solo fica exposta à ação erosiva das gotas de chuva por mais tempo e apresenta uma condição extremamente favorável à erosão, como foi comprovado em estudos realizados sob condições idênticas por Margolis et al. (1985) e Albuquerque et al. (2005). Esses dados ressaltam o importante papel que a cobertura vegetal pode desempenhar no controle das perdas de sedimento por escoamento superficial, principalmente quando considerada a irregularidade temporal e espacial das chuvas na região semiárida do Nordeste do Brasil. 


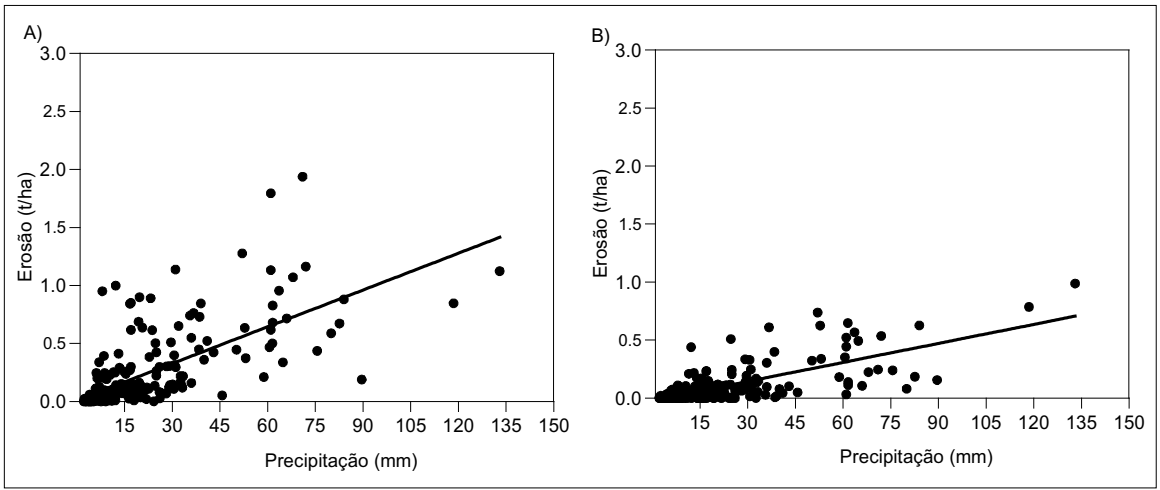

FIGURA 7 - Relação entre precipitação e erosão nas parcelas de São João do Cariri:

(A) Parcela 1, e (B) Parcela 2

Fonte: Santos et al. (2007).

Como a região semiárida é marcada pela distribuição pluvial temporal e espacial irregular, durante o período mais intenso das chuvas deve-se manter a superfície do solo coberta. Dessa forma, as perdas de solo e água podem ainda ser mais reduzidas, se faixas de vegetação permanente forem adotadas. Em todos os tratamentos testados neste trabalho, as perdas médias anuais de solo estiveram abaixo de 4 ton/ha, portanto, dentro do limite de tolerância para solos pouco profundos.

Para analisar a influência direta da cobertura vegetal na produção de sedimentos no solo do tipo Vertissolo Cromado, foram selecionados dois eventos de chuva mais representativos ocorridos na MB1. Os resultados selecionados mostram o comportamento dos hietograma e hidrograma observados, gerados sob chuvas típicas da região semiárida. A Figura 8 (A) mostra o evento do dia 15/2/2002, que se iniciou às $18 \mathrm{~h} 50 \mathrm{~min}$, teve duração de 4h40min, com escoamento começando 2 minutos após o início da chuva. O maior pico ocorreu 20 minutos depois de começar o escoamento superficial, produzindo um total de sedimentos da ordem de 0,2 ton/ha.

A Figura 8 (B) apresenta o evento do dia 06/03/2002, que começou às $12 \mathrm{~h} 06 \mathrm{~min}$, teve duração de $4 \mathrm{~h} 42 \mathrm{~min}$. O escoamento começou aproximadamente 4 minutos após o início do evento chuvoso, e o maior pico ocorreu 42 minutos após o início do escoamento superficial. Analisando a Figura 8 (B), percebe-se uma rápida resposta entre o tempo de empoçamento e o início do escoamento superficial, produzindo um total de 
sedimentos da ordem de 0,15 ton/ha. O hidrograma da Figura 8 (B) mostra comportamento semelhante ao do hidrograma da Figura 8 (A).

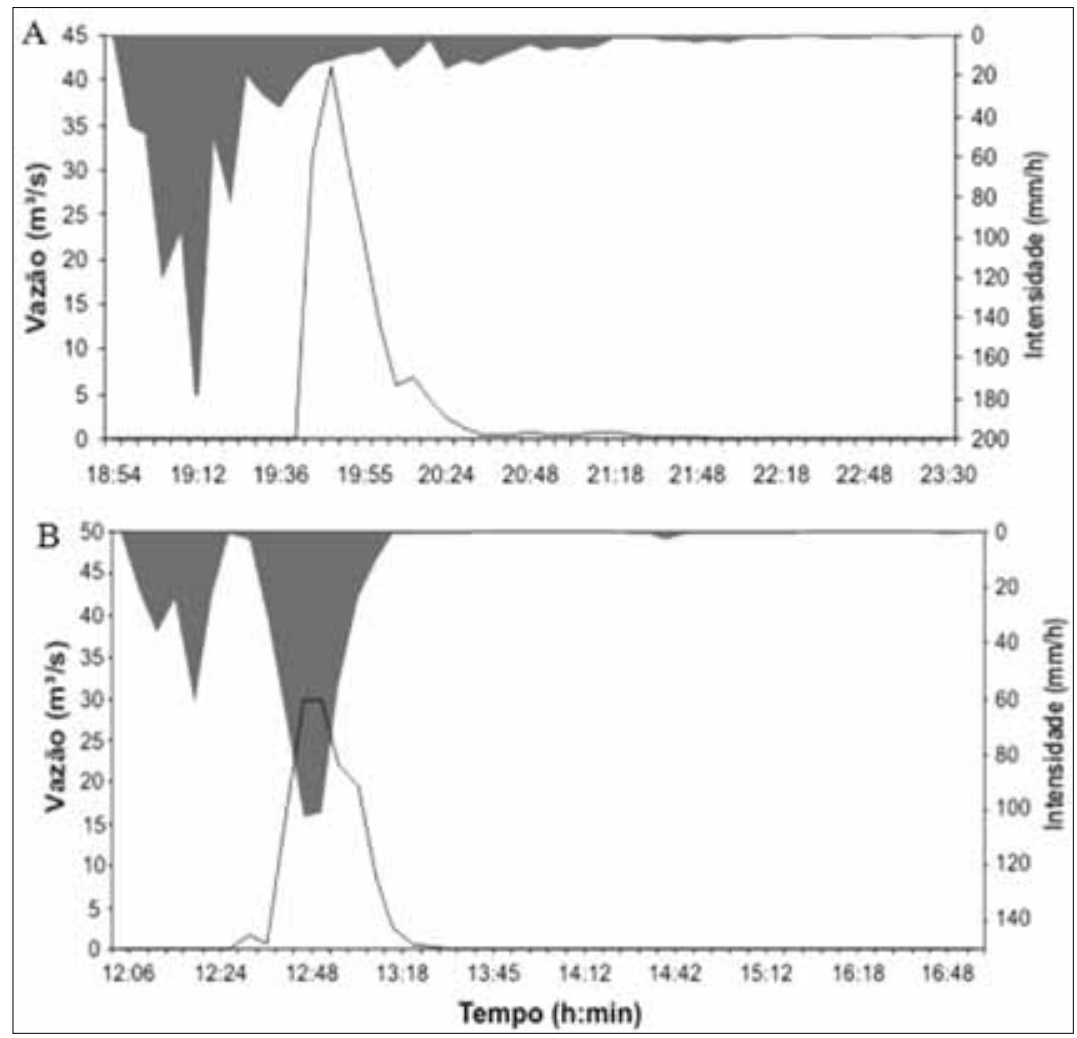

FIGURA 8 - Hietogramas das cheias de: (A) 15/2/2002 e (B) 6/3/2002, com hidrogramas registrados na $\mathrm{MB} 1$

Fonte: Srinivasan et al. (2004).

Como a MB1 é mantida com solo exposto, os processos hidrossedimentológicos são diretamente afetados pela falta de cobertura superficial, pois não ocorre a interceptação da água das chuvas pela vegetação, consequentemente, há menor presença de água retida nas folhas e galhos da vegetação e, portanto, ocorre menor evapotranspiração. Para Albuquerque et al. (2005), esse fato também pode ser explicado pela presença do pavimento desértico, que é uma característica dos solos Vertissolos, constitu- 
ídos de calhaus e matacões de quartzo, que servem como agente protetor, interceptando o impacto das gotas de chuva sobre o solo e, por conseguinte, interferindo diretamente no processo de escoamento superficial.

A Figura 9 mostra as perdas de sedimento e água anuais em função da precipitação média anual na MB1. Verificou-se que, em praticamente todos os anos, as perdas de água e sedimento tiveram grandezas muito próximas, com exceção no ano de 2000, que registrou valores de perdas de sedimento e água da ordem de 1,14 ton/ha e 92,72 mm, respectivamente.

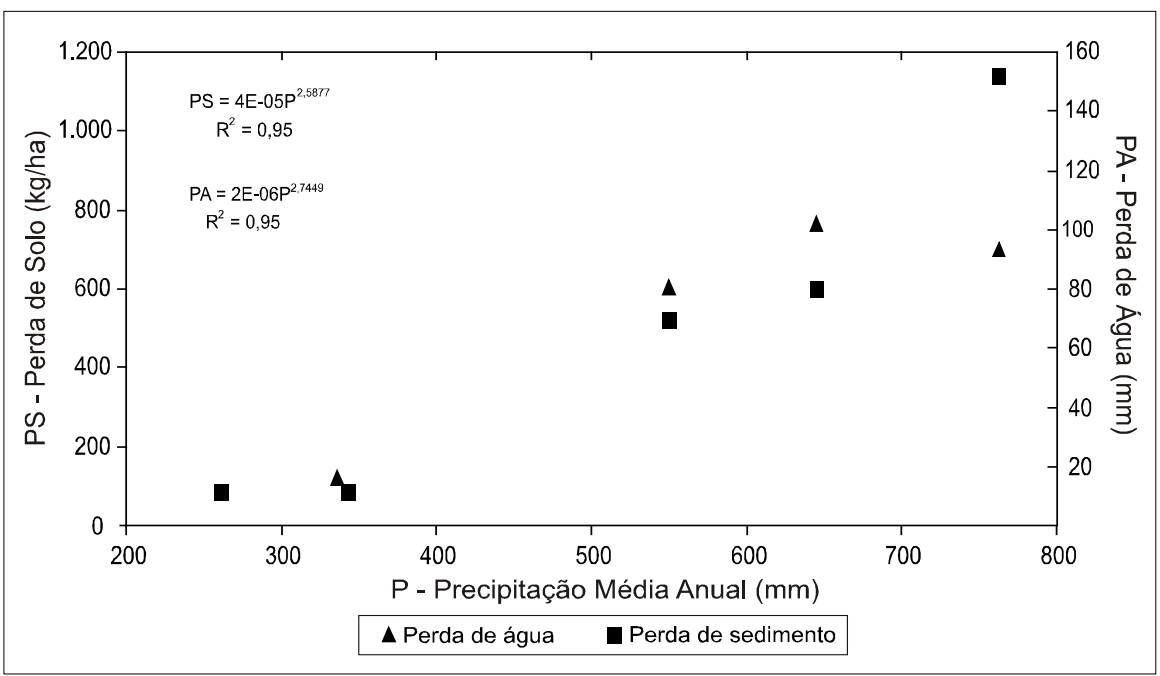

FIGURA 9 - Perdas de sedimento e água anuais em função da precipitação média anual na MB1

As precipitações na BESJC se caracterizam, na maioria dos eventos, por concentrarem a maior quantidade de chuva em um pequeno intervalo de tempo, caracterizando, desta forma, chuvas bastante erosivas (Cantalice et al., 2009). Assim sendo, Albuquerque et al. (2005) ressaltam o importante papel da cobertura vegetal no controle das perdas de água e sedimentos por escoamento superficial, principalmente quando se considera a irregularidade e a baixa precipitação pluvial da região semiárida no Nordeste do Brasil. Silva et al. (2005) enfatizam que os maiores valores de sedimentos carreados ocorrem na presença dos eventos com maior dura- 
ção e intensidade de precipitação e, consequentemente, maiores lâminas precipitadas.

Deve-se destacar que os solos na região semiárida apresentam características granulométricas e mineralógicas distintas de outros solos existentes no Brasil, e que a pequena espessura da camada de solo é condicionante para que chuvas com pequena duração, mas com significativa intensidade, causem eventos expressivos de perdas de água e solo.

\section{Considerações finais}

Este trabalho apresentou os resultados da análise das perdas de água e solo na BESJC, a partir de dados observados de da produção de sedimentos e lâmina escoada em diferentes coberturas superficiais, e em uma microbacia com solo exposto.

Os resultados da produção de sedimentos mostram que a erosão média na Parcela 1 foi de 0,22 ton/ha, enquanto na Parcela 2 foi de 0,09 ton/ ha, o que evidencia a influência da cobertura vegetal sobre o processo erosivo no semiárido. Sobre os valores observados de lâminas escoadas em São João do Cariri, nota-se que a Parcela 1 obteve uma lâmina escoada anual média igual a 7,73 mm, enquanto na Parcela 2 o valor médio observado foi de 5,89 mm. Com a eliminação da vegetação da superfície, os valores nas lâminas escoadas na Parcela 2 aproximaram-se dos valores da Parcela 1.

\section{Referências}

ALBUQUERQUE, A. W. et al. Determinação de fatores da Equação Universal de Perda de Solo nas condições de Sumé, PB. Revista Brasileira de Engenharia Agrícola e Ambiental, v. 9, n. 2, p. 180-188, Campina Grande, PB, 2005.

CANTAliCE, J. R. B. et al. Linhas isoerosivas do Estado de Pernambuco $-1^{\text {a }}$ aproximação. Revista Caatinga, v. 22, n. 2, p. 75-80, Mossoró, RN, 2009.

FREITAS, F. J. et al. Erosão em entressulcos sob caatinga e culturas agrícolas. Revista Brasileira de Ciência do Solo, v. 32, n. 4, p. 1743-1751, Viçosa, MG, 2008.

GUADAGNIN, J. C. et al. Perdas de solo, água e nitrogênio por erosão hídrica em diferentes sistemas de manejo. Revista Brasileira de Ciência do Solo, v. 29, n. 2, p. 277-286, Viçosa, MG, 2005.

MARGOLIS, E.; SILVA, A. B.; JACQUES, F. O. Determinação dos fatores da equação universal das perdas de solo para as condições de Caruaru-PE. Revista Brasileira de Ciência do Solo, v. 9, n. 1, p. 165-169, Viçosa, MG, 1985. 
MARTINS, S. G. et al. Perdas de solo e água por erosão hídrica em sistemas florestais na região de Aracruz-ES. Revista Brasileira de Ciência do Solo, v. 27, n. 3, p. 395-403, Viçosa, MG, 2003.

MMA - Ministério do Meio Ambiente. Diagnóstico da vegetação nativa do bioma Caatinga. Secretaria de Biodiversidade e Florestas. Departamento de Conservação da Biodiversidade. Biodiversidade da Caatinga, 2003. Disponível em: <http://ainfo. cnptia.embrapa.br/digital/bitstream/item/18267/1/Biodiversidade_Caatinga_ parte2.pdf>. Acesso em: 15 de junho de 2012.

SANTOS, C. A. G.; SILVA, R. M.; SRINIVASAN, V. S. Análise das perdas de água e solo em diferentes coberturas superficiais no semi-árido da Paraíba. OKARA: Geografia em debate, v. 1, n. 1, p. 16-32, João Pessoa, PB, 2007.

SANTOS, C. A. G.; SRINIVASAN, V. S.; SILVA, R. M. Evaluation of optimized parameter values of a distributed runoff-erosion model applied in two different basins. IAHS Publication, v. 292, p. 101-109, Londres, Inglaterra, 2005.

SANTOS, J. Y. G. et al. Análise das perdas de água e solo no semiárido paraibano utilizando simulador de chuva. Anais do XIX Simpósio Brasileiro de Recursos Hídricos, 2011, Maceió, ABRH, 2011.

SILVA, D. D. et al. Efeito da cobertura nas perdas de solo em um Argissolo Vermelho-Amarelo utilizando simulador de chuva. Engenharia Agrícola, v. 25, n. 2, p. 409-419, Jaboticabal, SP, 2005.

SILVA, R. M.; SANTOS, C. A. G.; SRINIVASAN, V. S. Perdas de água e sedimento em diferentes sistemas de manejo no semiárido da Paraíba. Mercator, v. 10, n. 21, p. 161-170, Fortaleza, 2011.

SOUZA, B. I.; SUERTEGARAY, D. M. A.; LIMA, E. R. V. Desertificação e seus efeitos na vegetação e solos do Cariri Paraibano. Mercator, v. 8, n. 16, p. 217-232, Fortaleza, 2009.

SOUZA, B. I.; SUERTEGARAY, D. M. A.; LIMA, E. R. V. Políticas públicas, uso do solo e desertificação nos Cariris Velhos (PB/Brasil). Scripta Nova, v. 14, n. 311, Barcelona, Espanha, 2010. Disponível em: <http:/www.ub.edu/geocrit/sn/sn-311. htm >. Acesso em: maio 2011.

SRINIVASAN, V. S. et al. Bacia Experimental de São João do Cariri - PB. In: Implantação de bacias experimentais no semi-árido - IBESA/FINEP/FUNPEC, 2004.

Richarde Marques da Silva - Doutor em Engenharia Civil pela Universidade Federal de Pernambuco - Professor da Universidade Federal da Paraíba.

Celso Augusto Guimarães Santos - Doutor em Engenharia pela Universidade de Ehime e pós-doutorado pela Japan Society for the Promotion of Science - Professor da Universidade Federal da Paraíba. 